This item was submitted to Loughborough's Institutional Repository (https://dspace.lboro.ac.uk/) by the author and is made available under the following Creative Commons Licence conditions.

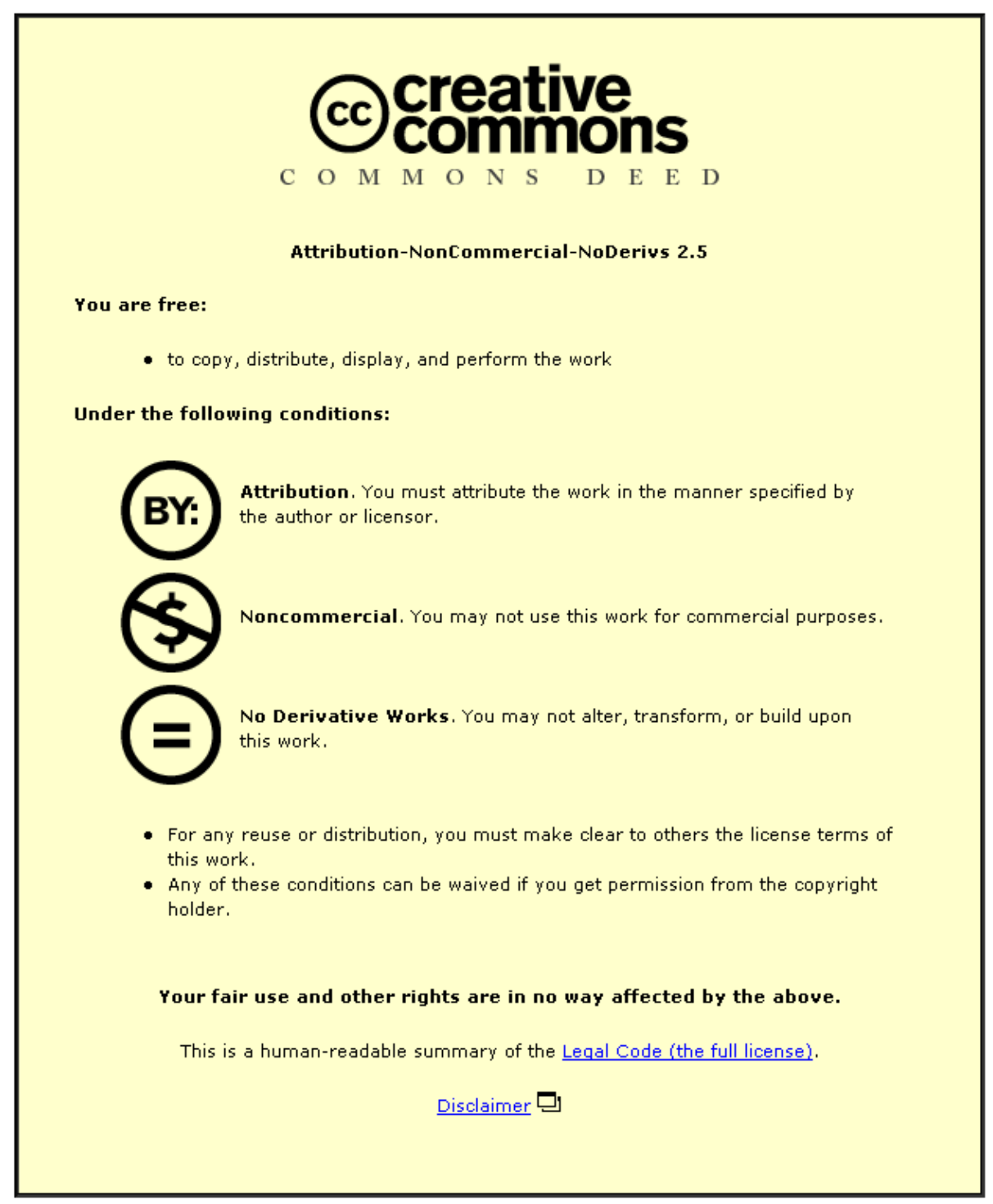

For the full text of this licence, please go to: http://creativecommons.org/licenses/by-nc-nd/2.5/ 
Paper title:

Authors:

(1)

Contact:

\section{Integrated Collaborative Design}

Simon A Austin BSc PhD CEng MICE FCS

Professor of Structural Engineering

Anthony Thorpe BSc MSc PhD MBCS MCIOB

Acting Head of Department

David S Root BSC MSc PhD MRICS MCIOB

Research Associate

Derek S Thomson BSc PhD

Research Associate

Jamie W Hammond BEng

Research Associate

Department of Civil and Building Engineering

Loughborough University

Loughborough

Leicestershire

LE11 3TU

Telephone: +44 (0) 1509222608

Fax: +44 (0) 1509223945

E-mail: s.a.austin@lboro.ac.uk 


\section{Synopsis}

This paper describes an approach to managing the supply chain from the perspective of design. It describes the concept of a Design Chain and argues that the industry needs to centre the development of Integrated Teams (as proposed in Accelerating Change) around collaborative working of all parties involved in the design process. Integrated Collaborative Design (ICD) recognises that we are too often focussed on the short-term objectives of projects, rather than long-term business strategy and organisational relationships. In simple terms, it involves three steps: identifying tasks (process management); allocating roles (as part of supply chain management); and focusing design solutions to deliver value. The paper outlines the principles and approach to ICD, which is supported by a handbook contain 25 supporting practice notes, published by Thomas Telford.

\section{The ICD project}

This paper presents a new approach to fostering integrated teams developed by the Integrated Collaborative Design (ICD) research project, a combined industry and academic initiative between Loughborough University and twelve construction companies with financial support from the EPSRC and the DTI as part of the LINK Integration in Design and Construction programme.

It presents new thinking in supply chain management derived from applied research, how this impacts on the flow of design information within projects, and its wider effect on strategic business relationships between companies that exist outside short term project relationships. This approach places the design processes and the management of design information at the centre of project management practice.

\section{The Need for Change}

\subsection{Role of Design}

The construction industry is adept at delivering highly complex products. It differs from much of engineering in that its products are often bespoke and respond to the specific needs of individual customers. These products are also generally assembled in unfamiliar locations. Construction projects involve relationships between many organisations and thousands of processes. The industry has evolved highly developed methods of accommodating this complexity, with the evolution of many specialised roles and embedded relationships. These are mediated through well-established contractual arrangements, while the delivery and assembly of components to dispersed locations is being continually refined with improving working methods and assembly technologies.

However, design - that part of construction that needs to be in place before the physical work can begin - remains an area where the complexity of the process is not well understood or managed as physical production. In much of the construction industry, the act of design takes place as an ill-defined process - a 'black box'. It occurs at a particular time in the project process, is performed by different parties and is creative. But, because it is poorly understood and managed. ICD is about understanding the act of design more fully, how design activities are dispersed through the supply chain and how these activities can be integrated across organisational and functional boundaries By developing this understanding, methods of managing business and project relationships can be established to reflect the complexity of design in the way it is managed and performed. This will create opportunities to improve customer satisfaction (by increasing customer value) and to promote the sustainability of construction businesses (by generating business value).

Customers demand that the industry improves project delivery and that it should learn from best practice, not only within construction, but also from other industries. One approach is to build 
what we have termed Design Chains. Design Chains provide a means for construction companies to understand and collaborate with each other to develop and propagate sustaining relationships that accommodate design process complexity. The collaborative development of project design information is an appropriate basis upon which to build these relationships.

The construction industry is beginning to respond to customer changes. The reports of Latham in 1994 [1] and Egan in 1998 [2] highlighted the need for this change and spurred the emergence of an appropriate industry climate for it to take place. Helping to drive this change is the use of information technology. Other sectors, including IT, automotive and aerospace industries have created new organisation forms (such as virtual companies) in which design responsibilities are distributed across the supply chain[3]. The dramatic productivity improvements achieved by these industries in the last 30 years have raised the question, particularly in the minds of construction industry customers, as to why construction has not similarly improved.

Most recently, some of the key issues in Rethinking Construction have been reaffirmed in Accelerating Change [4] which calls for the 'focussed delivery of value to the client through integrated teams'. This is an aspiration which resonates deeply with ICD. Following these reports, and with customers actively encouraging more innovative ways of working, construction has begun to establish new working practices, including supply chain management (SCM), benchmarking, lean production and total quality management (TQM).

We highlighted the need for improved design management as a means to improve the construction industry's ability to respond to the needs of its customers. However, the development of design management in construction (and other industries) has been hindered by the intuitive and iterative nature of the act of design. This makes it difficult to model, plan, and manage design in the same way as more sequential processes such as those concerned with the physical movement of goods or materials [5]. More sophisticated techniques and improved understanding are now being applied to the management of design. In recent years, for example, techniques derived from process-mapping research [6] have introduced rigour to decision-making in design planning previously restricted to other parts of the process.

New tools facilitate the use of design chains to structure management of design processes that span organisations which, in turn, can optimise the total design solution in the same way that supply chains have optimised the delivery of goods and services. Based upon the understanding of organisation relationships associated with an overarching design process, Integrated Collaborative Design provides design management methods and frameworks for collaborative working. ICD can help organisations integrate, helping them to achieve more together. Innovative approaches of this nature are required to meet the demands of customers who are beginning to view construction as another complex process (similar to those they manage themselves) requiring efficient and effective management.

Over time, the design and construction process has become progressively more fragmented due to the growth in specialisation and complexity of construction methods and technologies. This specialisation has increased the number of organisations and individuals with design responsibility within constructions project. The task today is to understand and distribute these processes across an integrated team of designers so they can be managed more effectively.

\subsection{Integrating Organisations}

When individual members of project design teams are distributed across different companies, a key challenge in design management is to manage the relationships between them. Organisational interfaces have always been problematic in construction and are often a source of dispute. Integrated Collaborative Design addresses this issue.

The tradition of single design disciplines in the construction industry has led to a situation where small firms, with limited skill bases, have to contend with a great variety of contractual arrangements and inter-firm relationships. Multidisciplinary firms or teams should be better able to provide integrated design. But, even when inter-organisational interfaces have been removed, historical design disciplines give rise to a silo-culture, where departments develop their own 
values and objectives, which may differ from those of the company. Just as design management can unite the different creative cultures that exist between organisations, so it can be used within organisations to optimise information flow between functional groups and design disciplines.

Historically, the industry sees construction contracts as the means of controlling relationships between project participants. This is often regardless of whether design is covered under the contract or whether it is generated separately through design commissions; procurement routes, such as design and build (D\&B) and design manage construct (DMC), have been attempts to secure contractual integration. Standard forms and conditions of contract have tended to focus on the possibility of failure, by defining the means and channels of communicating design (and other) information between the project parties and avenues of recourse. In trying to force design processes to fit in with these rigid structures, the contractual arrangements and the design process both begin to break down. Collaborative design requires an easy flow of information between all participants.

The need to improve design process management has been recognised by many consulting and contracting companies. Some of the latter, who offer various forms of design and build services, have realised that they must change the culture and management of design, in both their own organisations and those they work with. As a result, a number have recently undertaken major reviews of design management practice.

Four key areas are emerging that require attention when integrating design across organisations. They are the need to:

1. identify individual design tasks and the relationships between them;

2. allocate responsibility for completing design tasks to organisations on the basis of who is best placed to perform them (judged by technical competency and commercial capacity);

3. manage the smooth exchange of design information between collaborative partners; and

4. create working environments that aid the delivery process, such as networks of compatible organisations with shared values, cultures and ways of working.

ICD provides a framework and associated tools and techniques to address these issues within design management. This framework is structured around three principles, which provide a foundation for an organisation's practice of ICD and provide the premise for the application of the various practices that allow ICD to be adopted as an approach to design management [7].

\section{The ICD Approach}

\subsection{The basics}

Figure 1 provides an overview of ICD. Within the operating culture of a single organisation, the use ICD to structure design management is divided into two domains (the business and the project) and into two roles (provider and receiver ).

Three principles lie at the core of ICD:

- Applying process management

- Adopting supply chain management practices

- Establishing value frameworks 
Adopted in sequence by an organisation and progressively diffused into its operating culture, these principles build a common understanding and attitude among its individual members. The integration of these principles into an organisation's working ethos is a prerequisite for collaboration, as they guide the application of all other elements of the ICD approach.

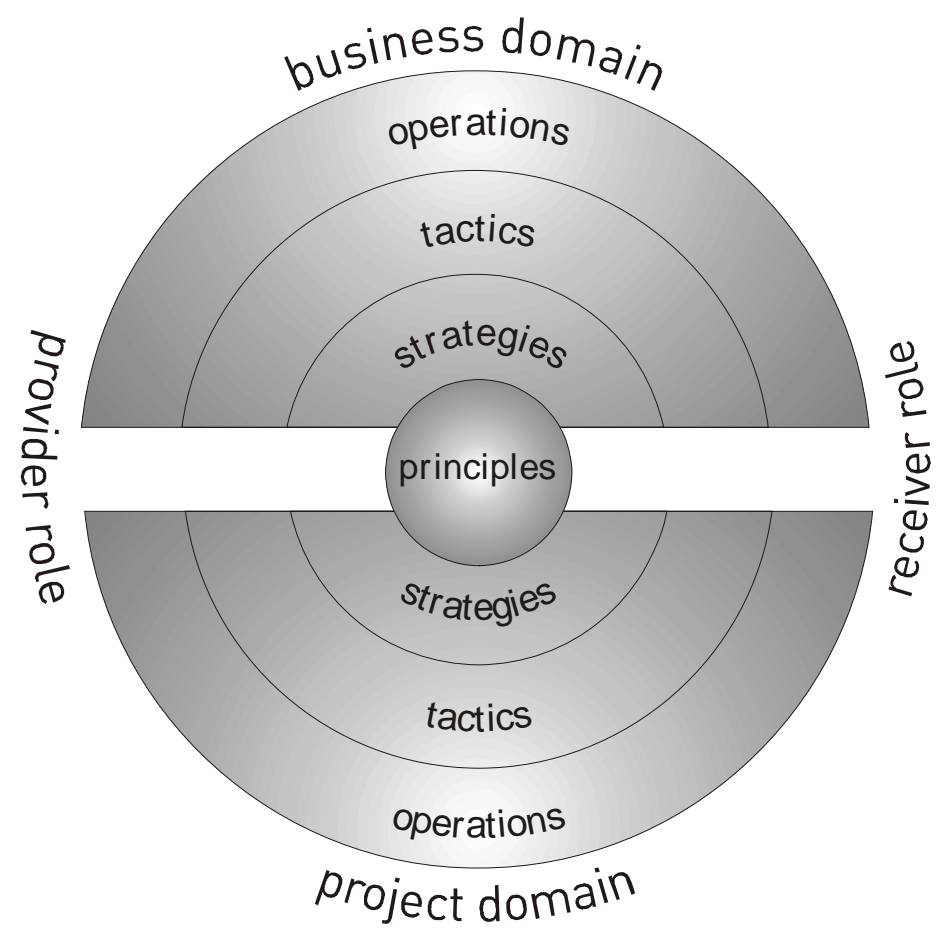

Figure 1 ICD Structure

The ICD practices encapsulate many of the findings and outputs of the research project underpinning ICD in the form of advice, approaches, tools and techniques. These practices are categorised into strategies, tactics and operations:

- ICD strategies help organisations plan their development of ICD practice.

- ICD tactics help organisations establish the working methods and resources required to respond to their strategic goals.

- ICD operations guide organisations in their integration of ICD in their everyday activity.

This precedence is irrespective of whether the practice occurs in the business domain or in the project domain, or whether it is used by a provider or receiver of design solutions

\subsection{The Business and Project Domains}

ICD business domain operations comprise the ongoing activities of organisations that give them structure. They span projects and establish the company in the market. Project domain operations, on the other hand, are temporary and occur when individuals and other resources come together to deliver individual projects. Examples of business domain activities include employee training, managing long-term customer relationships, maintaining alliances, business development and quality assurance. Examples of project domain activities include project management, value management and quality control.

The division between the business domain and the project domain is ambiguous. It is defined largely by the views that organisations and individuals have of themselves and of what they do. 
Some see the construction industry as being very task-focused, reflecting the emphasis placed on the highly technical and role-specific training that most individuals receive. However, this emphasis causes managers and designers to concentrate on project details at the expense of their organisation's wider business. Furthermore, the advent of the Private Finance Initiative and general growth of partnering are increasingly causing organisations to see major projects as separate business units.

Despite the subjective division between the domains, ICD highlights the importance of relationship planning and management in the business domain. It encourages the view of a business being concerned with the delivery of projects as an ongoing operation, rather than attempting to manage the delivery of individual projects as a sequence of individual events. Although business domain activities are vital to the survival of organisations, the extent to which they are formally defined is dependent on the nature of the organisation. In general, larger organisations are more formalised and may allocate responsibility for specific processes to dedicated staff, although the processes themselves tend to be generic across all organisation types (consider human resource management and legal department processes, for example). Some organisations may consider some of their processes to be more important than others due to the nature of their work and the markets they serve.

A balance must be struck between organisational relationships formed in the business and project domains. Traditionally, relationships are formed as a consequence of organisations working with each other on individual projects and, therefore, have historically been managed as a function of the project domain. This has caused organisations to give insufficient consideration to managing and sustaining long-term relationships in the business domain. Often this has meant that such activities have been informal, relying on personal relationships between individuals across different organisations. They have consequentially been hostage to the movement of people within the industry. This is not conducive to the operation of effective design chains.

ICD introduces structure to the otherwise ad-hoc business activities concerned with developing and maintaining long-term relationships between organisations. For example, an individual acting as a receiver of design solutions may, having developed a relationship with a provider in a project, be influenced by their performance and promote it for inclusion in the supply chain of subsequent projects. Currently, methods of capturing, filtering and maintaining knowledge about established and potential business partners are rarely developed much beyond simple databases or networks of personal relationships. Project domain relationships provide weak feedback into business domain relationships. An ICD approach addresses this by allowing business domain relationships to drive project domain relationships by establishing the capability and performance of business partners prior to the commencement of any particular project.

Irrespective of the nature of the work, many of the processes used by organisations in the project domain remain constant. They tend to be concerned with issues such as programme management, procurement, document control and resources. These processes have been extensively described and modelled by initiatives such as the RIBA Plan of Work [8] and the Process Protocol [9]. The latter work sought to establish a generic project process map for use as a framework to structure a common process and language between project collaborators. It provides a project management framework that helps organisations understand each other and work together better. This work on generic project processes has informed much recent work in supply chain integration by companies such as BAA, who have adopted framework partnership arrangements.

ICD is concerned with the influence that management has over the design process. It addresses the need for design management to be effective with techniques such as mapping the flow of design information at the project level while also nurturing business environments compatible with value-adding collaborative work. Within an ICD approach to design management, Design Chains establish a stable environment around projects and to aid the decision-making therein.

\subsection{The ICD Principles}

The purpose of the three ICD principles applied to design management are: 
1. to identify tasks - applying process management;

2. to allocate roles - adopting supply chain management practices; and

3. to focus design solutions and to hone process management - establishing value frameworks

The first two support the last, which represents the end game - the delivery of value to all stakeholders through an effective, integrated design.

By progressively adopting these principles (Figure 2) an organisation can evolve an ICD approach and hence be able to:

1. use design process modelling to understand design information flows and allocate design tasks between collaborating organisations appropriately;

2. build on its process models by establishing supply networks to group together organisations of known technical competency and allocate design responsibilities among them; and

3. integrate the processes of organisations within a supply network to build a value system.

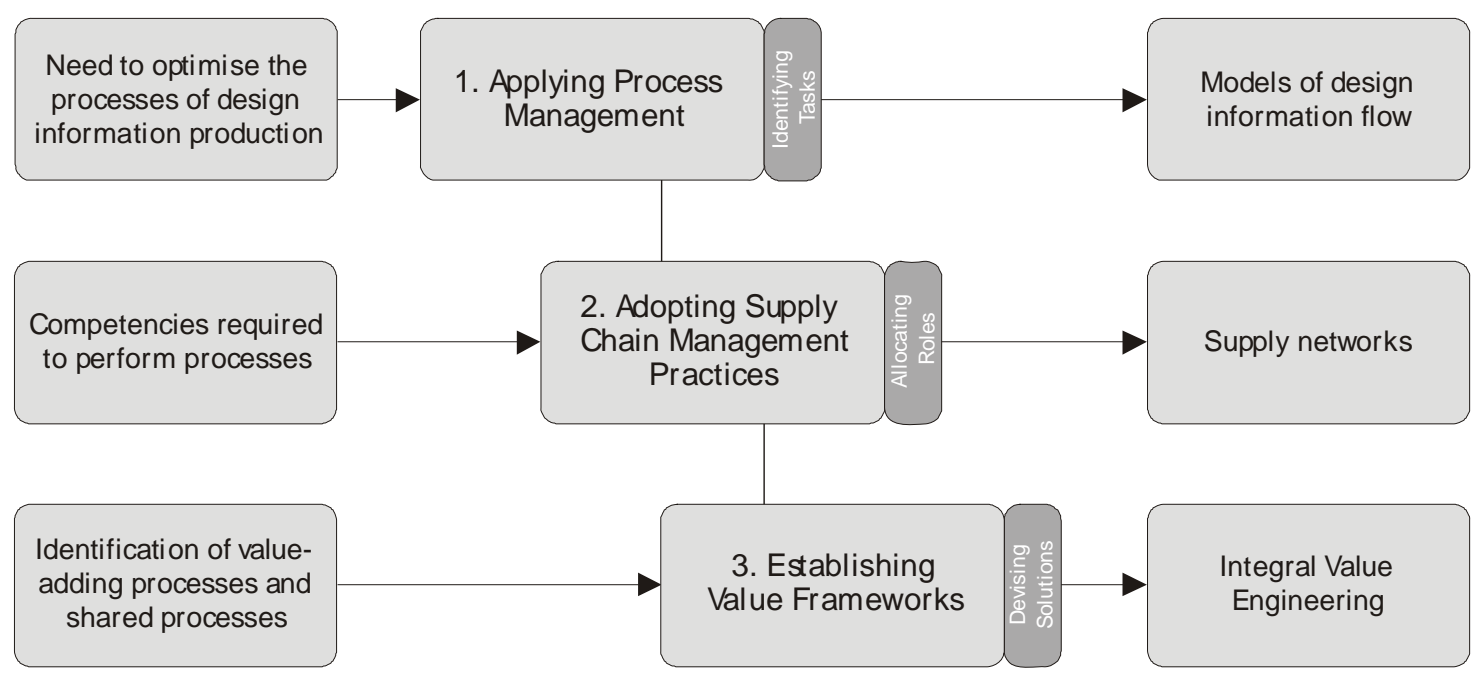

Figure 2 The relationship of the ICD principles

This approach means that organisations improve their ability to perform design in line with the principles of ICD by improving their business, rather than by introducing improvements to one project and attempting to replicate and add to them in subsequent projects. For example, in the project domain, supply chains are not dependent upon project processes in the same way that supply networks are dependent upon business processes.

A handbook has been produced [8] to help organisations progressively adopt and apply the three ICD principles. It includes 25 practices that can be used to structure an organisation's introduction of the ICD principles into their everyday work.

In many cases, the adoption of ICD by a design organisation necessitates a significant shift in attitudes. The approach recognises that a barrier to successful change is the tendency to retreat into existing ways of thinking, such as the idea that all projects are prototypes and unique. To overcome this, ICD looks at construction projects in terms of their similarities and seeks to build upon them (for example, by seeing a building as a unique assembly of standard components within technical systems). ICD allows companies to replicate management processes, while also learning and revising those processes to include lessons learned from working collaboratively.

The construction industry differs from other areas of engineering, such as the car industry or computing, in that new technology has had less impact on its production processes. For example, 
while the introduction of automation to car manufacture has revolutionised that industry, the introduction of cutting edge technology into buildings (such as the use of computational fluid dynamics to develop passive ventilation systems) alters the construction method little - although it does make for a more comfortable and efficient product. Construction is still largely a craft-based industry, in stark contrast to the advanced manufacturing and assembly processes of industries such as the microelectronic and aerospace sectors.

As a result, the working methods have remained relatively unchanged throughout the last 50 years although projects themselves have become more complex and the construction industry more global. One consequence is that many attitudes held by both individuals and organisations have lagged behind the innovative working practices that have been pioneered elsewhere. The construction industry has been the poorer for it. A typical example is the construction industry's classification of organisational types. Labels such as 'consultant', 'contractor' and 'supplier' are loaded terms. They carry a weight of historically shaped behaviours. Despite the growing expectation for suppliers to undertake design, the industry tends to cling to these stereotypes and continues to describe organisations with outdated labels that do not always reflect their roles.

By adopting the ICD principles, construction organisations can avoid these pitfalls through a generic language that can be used by all organisations, irrespective of their function, size or traditional position in the industry. By focusing on the exchange of design information within the design chain, ICD provides a basis for the management of organisational involvement in design according to technical expertise, rather than traditional role. In part, this is achieved through the adoption of a new language that does not rely on traditional role descriptions and thereby avoids their connotations. In doing so, it has a similar approach to the Building Down Barriers initiative [10] which describes all members of the supply chain as 'suppliers' regardless of how their role would be traditionally described.

Unlike Building Down Barriers and other partnering initiatives [11] which presuppose a specific type of contractual relationship, ICD does not restrict itself to a particular procurement route. Instead, the approach establishes three principles at the core of an organisation's business that can be applied to all the projects that the organisation undertakes.

\subsection{The ICD Practices}

ICD practices are divided into Strategies, Tactics and Operations, whose purposes are to plan, to respond and to do. Figure 3 summarises the 25 practices provided in the handbook.

The strategies help plan the development of an organisation's ICD practice over time to establish working relationships centred on collaborative design. Unlike general business strategies, ICD's are not concerned with diversifying an organisation's core competencies nor with developing new ones. Instead, they are concerned with managing the manner by which its current competencies are linked with the organisations it works with.

Tactical practices help organisations establish the right infrastructure, including the deployment of tools and training. They make them ready for action. Tactics are divided into those that address long-term ICD strategies in the business domain and those that are better suited to achieving short-term objectives in the project domain.

Operational practices help organisations introduce ICD principles to their everyday business and project activities. Some operations provide guidance to help organisations introduce novel approaches for which new skills must be learnt, while others introduce management approaches established elsewhere into an organisation's ICD practice.

ICD business domain operations should then feedback to an organisation's strategy, including ICD strategies. Part of this process involves reviewing the feedback from projects and, where necessary, making appropriate strategic adjustments to incorporate new knowledge derived from projects.

The origins of the practices and associated tools are diverse. Some include, or are based upon, well-established methods, either in construction or other industries. In the latter case they are yet 
to be widely established in construction. Other practices have been developed during the ICD research project and related research projects. These represent more novel ideas geared to help organisations innovate. The practices are by no means exhaustive and compliment many other good methods and tools.

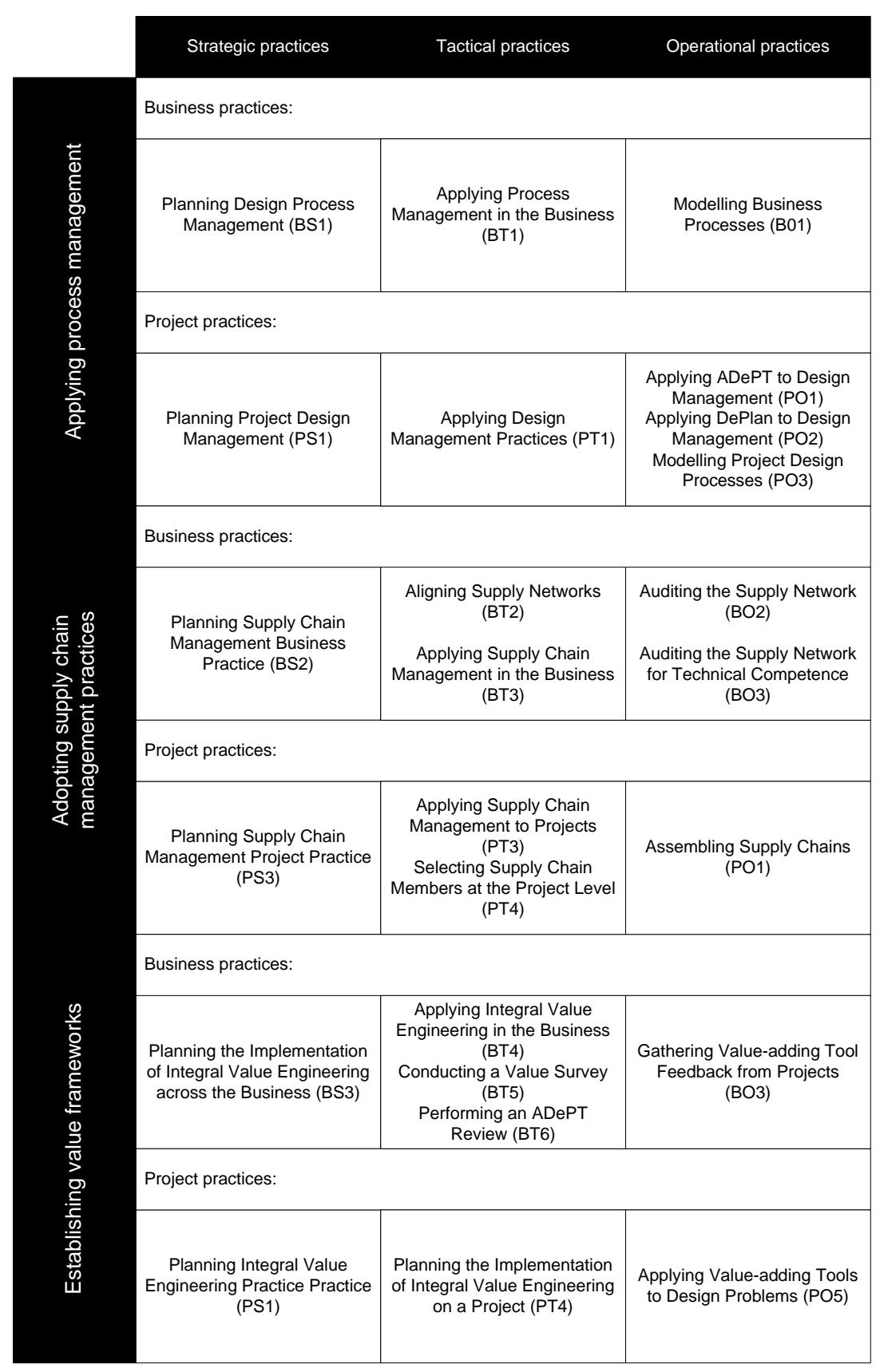

Figure 3 The ICD strategic, tactical and operational practices support the three ICD principles

Each practice has a time and place that depends not only on the specifics of a project, but also on the maturity of the business wishing to deploy them. To help in the latter a simple maturity assessment table has been developed for each of the three ICD principles. Figure 4 shows the 
one for Applying Process Management. Individuals and groups with an individual organisation or across companies in a supply network can use this approach to identify how far they have progressed in each area and hence determine a suitable strategy for adopting the ICD principles and practices.

\begin{tabular}{|c|c|c|c|c|c|c|}
\hline & Level 1 & Level 2 & Level 3 & Level 4 & Level 5 & Level 6 \\
\hline & Don't Know & $\begin{array}{l}\text { Haven't thought } \\
\text { about it }\end{array}$ & $\begin{array}{l}\text { Thinking of doing } \\
\text { something about } \\
\text { it }\end{array}$ & $\begin{array}{c}\text { Doing it as } \\
\text { normal business }\end{array}$ & $\begin{array}{l}\text { Full deployment } \\
\text { and } \\
\text { improvements }\end{array}$ & $\begin{array}{c}\text { Inherent practice } \\
\text { throughout } \\
\text { operations }\end{array}$ \\
\hline $\begin{array}{l}\text { Understanding Project } \\
\text { Processes }\end{array}$ & $\begin{array}{l}\text { No } \\
\text { understanding of } \\
\text { project process }\end{array}$ & $\begin{array}{l}\text { Project use } \\
\text { processes } \\
\text { defined by } \\
\text { contract }\end{array}$ & $\begin{array}{l}\text { Recognise that } \\
\text { existing } \\
\text { processes need } \\
\text { development }\end{array}$ & $\begin{array}{l}\text { Seeking } \\
\text { alignment of } \\
\text { project } \\
\text { processes }\end{array}$ & $\begin{array}{l}\text { Coherent project } \\
\text { processes well } \\
\text { established } \\
\text { between } \\
\text { organisations }\end{array}$ & $\begin{array}{l}\text { Consistent } \\
\text { project } \\
\text { processes } \\
\text { developed and } \\
\text { aligned with } \\
\text { competencies }\end{array}$ \\
\hline $\begin{array}{l}\text { Modelling Project } \\
\text { Processes }\end{array}$ & $\begin{array}{l}\text { No knowledge of } \\
\text { process } \\
\text { modelling }\end{array}$ & $\begin{array}{l}\text { Individual } \\
\text { businesses } \\
\text { define own } \\
\text { processes }\end{array}$ & $\begin{array}{l}\text { Consistent work } \\
\text { breakdown } \\
\text { structures } \\
\text { recognised }\end{array}$ & $\begin{array}{l}\text { Generic } \\
\text { processes } \\
\text { established and } \\
\text { used }\end{array}$ & $\begin{array}{l}\text { Shared work } \\
\text { breakdown } \\
\text { structures are } \\
\text { understood and } \\
\text { utilitised }\end{array}$ & $\begin{array}{l}\text { Processes } \\
\text { modelled and } \\
\text { tasks aligned }\end{array}$ \\
\hline $\begin{array}{l}\text { Aligning } \\
\text { Organisational } \\
\text { Interfaces }\end{array}$ & $\begin{array}{l}\text { No attempts to } \\
\text { define interfaces }\end{array}$ & $\begin{array}{l}\text { Inconsistent } \\
\text { allocation of } \\
\text { tasks with } \\
\text { significant } \\
\text { interface } \\
\text { problems }\end{array}$ & $\begin{array}{l}\text { Design overlaps } \\
\text { and gaps } \\
\text { recognised in } \\
\text { critical areas }\end{array}$ & $\begin{array}{l}\text { Task allocation } \\
\text { between all } \\
\text { organisations } \\
\text { based on know } \\
\text { interfaces and } \\
\text { competencies }\end{array}$ & \begin{tabular}{|l|} 
Seamless \\
transfer of \\
information \\
without gaps or \\
overlaps
\end{tabular} & $\begin{array}{l}\text { Fully aligned } \\
\text { interfaces with a } \\
\text { just-in-time } \\
\text { release of } \\
\text { information }\end{array}$ \\
\hline $\begin{array}{l}\text { Enhancing Design } \\
\text { Information Co- } \\
\text { ordination }\end{array}$ & $\begin{array}{l}\text { Design } \\
\text { information } \\
\text { exchange is not } \\
\text { effectively } \\
\text { managed or } \\
\text { monitored }\end{array}$ & $\begin{array}{l}\text { Design information } \\
\text { is 'pushed' to all } \\
\text { parties } \\
\text { indiscriminately, } \\
\text { regardless of need } \\
\text { based on contracts }\end{array}$ & $\begin{array}{l}\text { Recognised } \\
\text { overload of } \\
\text { information flow } \\
\text { and need to } \\
\text { realign } \\
\text { processes }\end{array}$ & $\begin{array}{l}\text { Design } \\
\text { information } \\
\text { shared in } \\
\text { common formal } \\
\text { with clear } \\
\text { understanding of } \\
\text { needs }\end{array}$ & $\begin{array}{l}\text { Information needs } \\
\text { of each } \\
\text { organisation } \\
\text { understood with } \\
\text { predominately 'pull' } \\
\text { transfers of } \\
\text { essential } \\
\text { information } \\
\text { only }\end{array}$ & $\begin{array}{l}\text { Fully co- } \\
\text { ordinately needs } \\
\text { expressed } \\
\text { including 'what' } \\
\text { and 'why' it is } \\
\text { important }\end{array}$ \\
\hline $\begin{array}{l}\text { Establishing Project } \\
\text { Transparency }\end{array}$ & $\begin{array}{l}\text { Silo mentalities } \\
\text { predominate }\end{array}$ & $\begin{array}{l}\text { Obscured roles } \\
\text { and poor } \\
\text { communication } \\
\text { cause significant } \\
\text { delays to } \\
\text { projects }\end{array}$ & $\begin{array}{l}\text { Communication } \\
\text { problems } \\
\text { recognised as } \\
\text { cause of poor } \\
\text { performance on } \\
\text { projects }\end{array}$ & $\begin{array}{l}\text { Project roles are } \\
\text { well defined and } \\
\text { communicated }\end{array}$ & $\begin{array}{l}\text { Mutual } \\
\text { agreement of } \\
\text { roles is } \\
\text { established as } \\
\text { basis for co- } \\
\text { ordination }\end{array}$ & \begin{tabular}{|l|} 
Fully effective \\
communication \\
based upon \\
clarity of roles \\
and \\
responsibilities
\end{tabular} \\
\hline $\begin{array}{l}\text { Fostering Project } \\
\text { Learning }\end{array}$ & $\begin{array}{l}\text { No } \\
\text { acknowledgeme } \\
\text { nt of the impact } \\
\text { of projects on } \\
\text { delivery }\end{array}$ & \begin{tabular}{|l|} 
Problems recur \\
on successive \\
projects causing \\
poor \\
performance and \\
delays
\end{tabular} & $\begin{array}{l}\text { Mechanisms } \\
\text { exist for } \\
\text { capturing } \\
\text { feedback from } \\
\text { individual } \\
\text { projects }\end{array}$ & $\begin{array}{l}\text { Feedback from } \\
\text { projects is } \\
\text { consistently } \\
\text { captured and } \\
\text { shared }\end{array}$ & $\begin{array}{l}\text { Feedback is } \\
\text { managed } \\
\text { collaboratively } \\
\text { across projects }\end{array}$ & $\begin{array}{l}\text { Project based } \\
\text { learning is fed } \\
\text { back to business } \\
\text { relationships to } \\
\text { improve future } \\
\text { project } \\
\text { performance }\end{array}$ \\
\hline & & & & & & \\
\hline
\end{tabular}

Figure 4 Maturity Assessment for Applying Process Management

\section{The ICD Principles}

This section describes the principles in detail and their inter-relationship.

\subsection{Applying Process Management}

There are a series of activities that repeat between construction projects. This means that design tasks, and their information requirements, can be recorded to produce a generic design process model. By applying process management, collaborating organisations can represent the complex 
relationships between them in definitive terms. This increases their understanding of business and project activities and the nature of their corresponding relationships. By defining their generic design processes, and the flow of information within those processes, organisations can share these definitions with business partners to build a better common understanding of each other's design capabilities, roles and responsibilities.

Furthermore, process management creates opportunities to involve organisations in the design process according to their design expertise rather than their traditional contractual role. Design overlaps and/or gaps in the scope of project works can also be minimised (Figure 5). Having a common process view improves the relationships between collaborating organisations and helps project teams to plan operational activities with greater certainty and reliability. This minimises the 'fuzzy edges between consultants and specialist engineering contractors' [1].

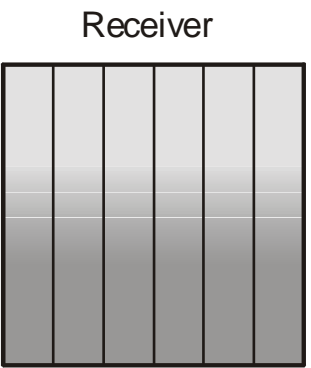

Provider

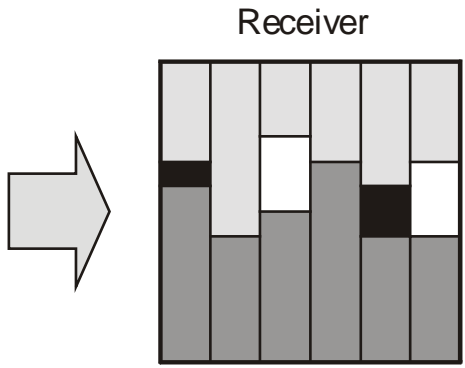

Provider

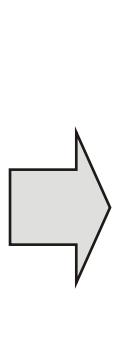

Provider

\section{Figure 5 Aligning organisations using design process models}

Collaborative strategies can be established between design chain members that reflect common understanding of the flow of design information between them. Latham [1] made the point that, if individual design processes can be identified, the responsibility for completing them can be allocated between collaborating organisations. In fact, he made specific reference to a guidance document on the allocation of design responsibilities being produced at that time by BSRIA [12] as an exemplar for the construction industry.

\subsection{Adopting Supply Chain Management Practices}

After applying process management, organisations are ideally positioned to assemble a design chain from their supply chain relationships. The object is to make the sum greater than the parts and this is done by organisations integrating their design competencies with one another.

Design information should be exchanged between project parties in a similar way to the transfer of goods within the supply chains of other industries. Not surprisingly, ICD adopts many SCM practices. In applying these to construction, an important distinction must be made between supply chains and supply networks (Figure 6). A supply network is a group of organisations with known competencies (technical and/or managerial). These organisations will have previously worked together and exhibit a degree of mutual understanding that has arisen from past experience. In contrast, a supply chain is a project-specific group of organisations consciously brought together to provide all the competencies required to complete a project. These are oneoff arrangements largely, though not exclusively, drawn from a common supply network. 


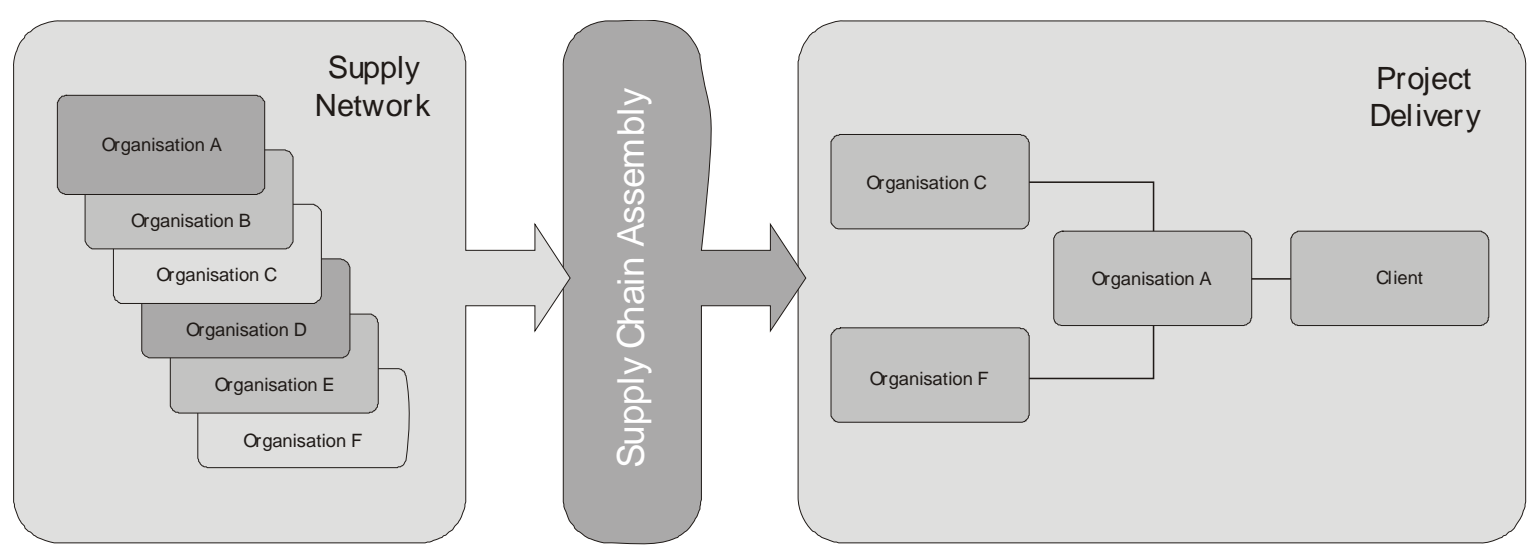

Figure 6 Relationship of a supply network and a supply chain

The distinction between supply chains and supply networks is a reflection of the project-based nature of the construction industry. In other industry sectors supply chains and supply networks are synonymous due to constant interaction associated with the delivery of a stream of goods. In construction, the flow of orders or contracts is intermittent. Consequently, there is a clearer distinction between business and project relationships.

\section{Information-based Supply Chain}

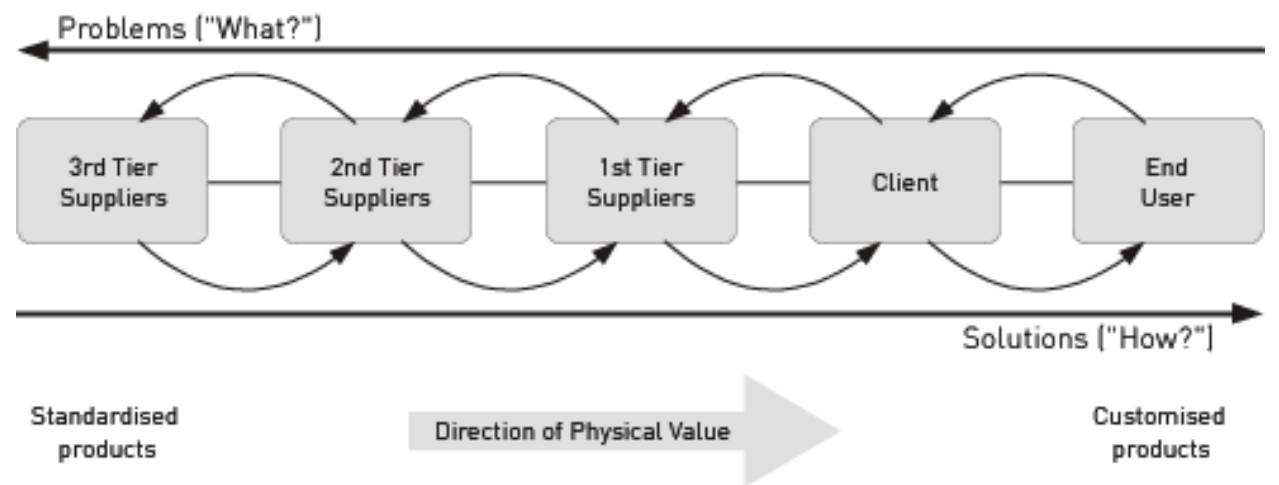

\section{Figure 7 A design chain}

A design chain is a specialised form of supply chain, in which information flows in both directions, often iteratively (Figure 7). This is in contrast to a product-based supply chain where information (in the form of purchase orders or performance specifications) flows down the chain and product flows back to the user. By viewing a project as a design chain, the organisations within it can manage their contribution to its function according to the roles of their individual employees as either providers or receivers of design information. Thus, by identifying the design chain associated with a particular construction project and identifying the design processes within it, ICD applies SCM principles to both the business and project domains. In the business domain the ICD principle of adopting supply chain management practices guides the selection of collaborators. In the project domain, the principle guides the identification of supply network members with the required technical and managerial competencies and informs the their assembly into project-specific supply (and design) chains. 


\subsection{Establishing Value Frameworks}

The final stage in the progression of an organisation's ICD practice is concerned with establishing value frameworks. These frameworks contain stronger business relationships that those established when adopting supply chain management practices. They allow project resources to be used more effectively to promote the delivery of value from collaborative design. A variety of working methods combine to form a coherent approach to value delivery (Figure 8).

\section{Business Domain}

\section{Project Domain}

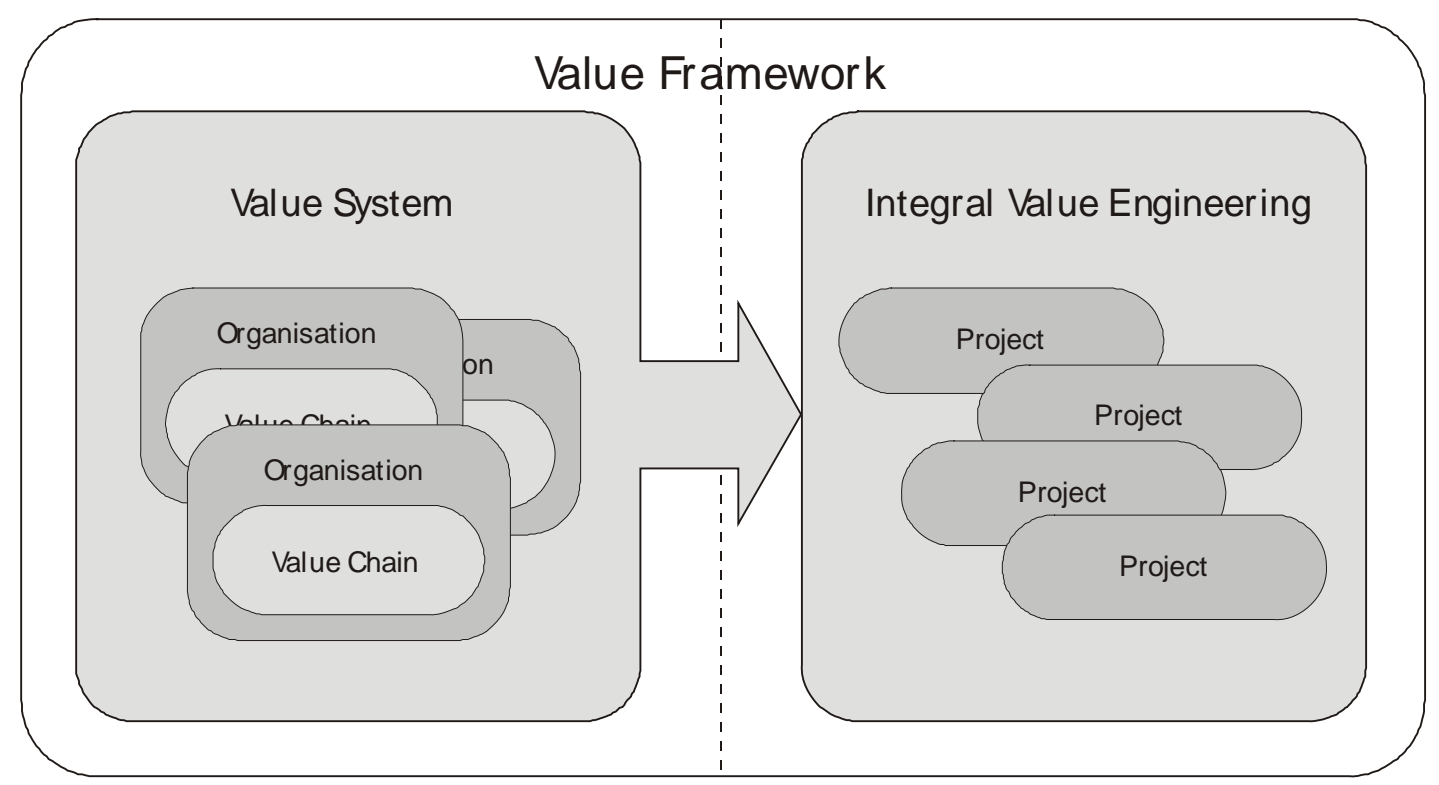

Figure 8 Relationship of value framework, systems and chains

Building value frameworks begins with an organisation's value chain [123. This structures a review of the organisation's internal processes to determine which generate project value. By using the ICD value chain model to better understands its own processes a company can negotiate in sharing out business tasks so that the processes of collaborative design work can be optimised.

The value chain model ensures that (ideally) the core processes retained by an organisations within a value framework are those that contain its unique design expertise and which therefore justify its inclusion in the project design chain. Porter's [12] value chain has been adapted to classify processes according to an organisation's ability to deliver internal business value through its involvement in project design chains (Figure 9).

Value systems reduce overhead costs and improve the overall efficiency of collaborating organisations by integrating their processes to rationalise common activities. This integrated function is applied to projects through the project design chain. In the same manner as supply networks, value systems exist within an organisation's business domain and influence project domain activity. 


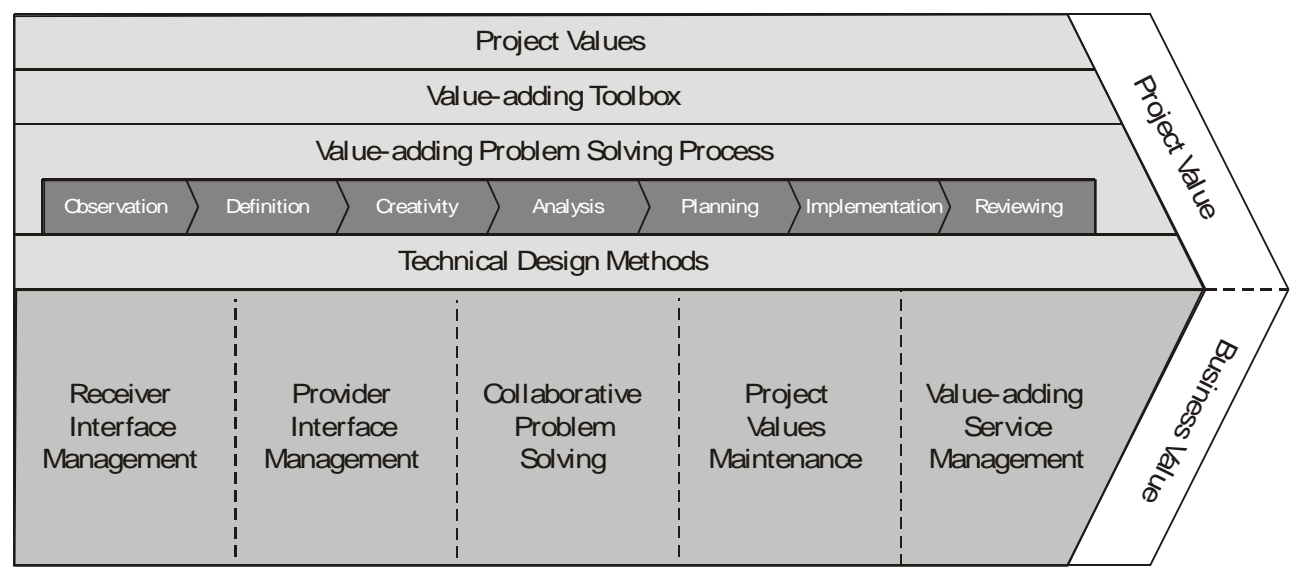

Figure 9 The ICD value chain

The use of value chains to align strategic business partners, and the building of value systems between supply network members, is commonplace in several of industries. These rationalisations are concerned with the elimination of waste when physical items are transferred from one place to another. In the same way, ICD value systems are concerned with eliminating waste when design information is exchanged. This process optimisation should deliver business value to value system members and project value to both design chain members and to the customer procuring construction industry products.

\section{Conclusion}

This collaborative research project has developed a view of how the industry could move forward and work together in a more integrated fashion to design and deliver products. Some ideas are common sense and others represent new ideas, at least to the construction industry. ICD provides a cohesive framework in which many current business improvement methods can be harnessed to provide benefits to construction organisations and hence deliver greater value to its customers.

\section{Acknowledgement}

The authors acknowledge the support of the EPSRC and DTI through the LINK Integration in Design and Construction Programme, together with that of the industrial collaborators: AMEC, Briggs Roofing and Cladding, Colt International, Crown House Engineering, Environmental Air Contracts, E-Squared, Galloway Group (Northern) Hathaway Roofing, Hilton Building Services, Honeywell, MSS Clean Technology and Senior Hargreaves.

\section{References}

1 Latham, M Constructing the Team, Joint Review of Procurement and Contractual Arrangements in the United Kingdom Construction Industry, HMSO, London (1994).

2 Egan, J Rethinking Construction, Report of the Construction Task Force to the Deputy Prime Minister, John Prescott, Department of the Environment, Transport and the Regions, London (1998).

3 Womack, J P, Jones, D T, Roos, D The Machine That Changed The World, Macmillan, New York (1990).

4 Strategic Forum for Construction Accelerating Change, chair by Sir John Egan, Rethinking Construction, Construction Industry Council, London (2002).

5 Austin S A, Baldwin A N and Newton A J, 'A data flow model to plan and manage the building design process', Journal of Engineering Design, 1996 Vol. 7, March, No. 1, pp 3-25. 
6 Austin, S, Baldwin, A, Li, B and Waskett, P Integrating Design in the Project Process, Proceedings of ICE: Civil Engineering, (2000) Volume 138, pp 172-182.

7 Austin, S, Baldwin, A, Hammond, J, Murray, M, Root, D, Thomson, D and Thorpe, A Design Chains: a handbook for Integrated Collaborative Design, Thomas Telford, London (2001).

8 Royal Institute of British Architects The Architect's Plan of Work for the Procurement of Feasibility Studies, a Fully Designed Building Project, Employer's Requirements or Contractor's Proposals, RIBA Publications, London (2000).

9 The Generic Design and Construction Process Protocol, www.processprotocol.com.

10 Holti, R, Noicolini, D, Smalley, M The Handbook of Supply Chain Management, Tavistock Institute, CIRIA, London (2000).

11 Bennett, J, Hayes, S The Seven Pillars of Partnering: A guide to second generation partnering, Thomas Telford, London (1998).

12 Parsloe, C J Allocation of Design Responsibilities for Building Engineering Services - a Code of Conduct to Avoid Conflict, TN 21/97, BSRIA, Bracknell, UK (1997).

13 Porter M E Competitive Advantage: Creating and Sustaining Superior Performance, The Free Press, New York (1985). 


\section{LIST OF FIGURES}

Figure $1 \quad I C D$ Structure

Figure 2 The Relationship of the ICD principles

Figure 3 The ICD strategic, tactical and operational practices support the three ICD principles

Figure $4 \quad$ Maturity Assessments for Applying Process Management

Figure $5 \quad$ Aligning organisations using design process models

Figure $6 \quad$ Relationship of a supply network and a supply chain

Figure $7 \quad$ A design chain

Figure 8 Relationship of value framework, systems and chains

Figure 9 The ICD value chain 